\title{
Leaders Lacking Emotional Intelligence: Towards A Theory Of Tobephobic Leaders
}

Prakash Singh, D. Ed, Nelson Mandela Metropolitan University, South Africa

\begin{abstract}
Does a theory on tobephobic leaders (TLS) exist? In attempting to advance a theory on TLs, it is very pertinent to ask: Who are intelligent leaders? Research strongly suggests that intelligent leaders can mean numerous things because this conceptualization of intelligent leaders can be based exclusively on their intellectuality (cognitive abilities - IQ), or their emotionality (emotional intelligence -EQ), or a combination of both. Expectedly, leaders who intellectualize and depend solely on their cognitive skills would tend to avoid the conscious recognition of the emotional basis of their decisions by substituting a superficially plausible, but questionable, explanation for their workers. On the other hand, leaders who base their decisions solely on their emotions can be accused of being irrational and not being task-oriented. The complexities of modern organizations in the twenty-first century require a new focus on leadership that extends well beyond possessing cognitive abilities alone.

The focus of this paper is to advance a theory of TLs because no such attempt has yet been made globally. The primary objective of this article is to expand the notions of leadership that are currently in practice in organizations. Such a theory could make a major impact on how we view leadership practices in different organizations and could, therefore, make a significant contribution to our understanding of leadership activities. The theory of TLs will be embedded in two dimensions of leadership: intellectuality and emotionality. Hence, relevant research will be cited to evoke the prevalence and effects of TLs on human resources.
\end{abstract}

Keywords: Tobephobic Leaders; Leaders' Tobephobic Intellectuality; Leaders' Tobephobic Emotionality; Tobephobic Workplace Experiences

\section{INTRODUCTION}

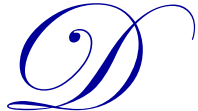

oes a theory on tobephobic leaders (TLs) exist? Recent research on emotional intelligence has attracted much attention in how leaders can be construed in their organizations because the traditional notion of leaders being in control using bureaucratic means has come under the spotlight. The definition of leaders having specific cognitive abilities seems no longer valid as research suggests (Goleman, 2011; Bliss, 2006; Caruso \&Salovey, 2006; Singh, 2005; Singh \& Manser, 2008). Recent research studies strongly suggest that the flip side of collegial leadership is tobephobic leadership (Singh 2013a; 2013c; 2013d; 2013g). Singh (2013e) aptly states that in "the latter situation, traditional bureaucratic management strategies create minimal opportunities for employees to be part of the normal decision-making process in organizations" (p. 1618). The primary objective of this paper is to advance a theory of TLs because no such attempt has yet been made globally, and, therefore the objective of this article is to expand the notions of leadership activities that are currently in practice in organizations. Such a theory can make a major impact on how we view leadership practices in any organization (private or public sector), and could, therefore, make a significant contribution to our understanding of leadership strategies. In attempting to advance this theory on TLs, it is very pertinent to ask: Who are intelligent leaders? Research (Mayer \& Salovey, 1997; Goleman, 2011; Sterrett, 2000; Singh, Manser \& Dali, 2013; Singh, 2013e) strongly suggests that intelligent leaders can mean numerous things because this conceptualization of intelligent leaders can be based exclusively on their intellectuality (cognitive abilities - IQ), or their emotionality (emotional intelligence - EQ), or a combination of both. Expectedly, leaders who intellectualize and depend solely on their cognitive skills would tend to avoid the conscious recognition of the emotional basis of their decisions by substituting a superficially plausible, 
but questionable, explanation to their workers (Merriam-Webster's Medical Dictionary, 2006, p. 362). On the other hand, leaders who base their decisions solely on their emotions can be accused of being irrational and not being task-oriented. Hence, in this paper, the theory of TLs that will be advanced will focus primarily on two dimensions of leadership: intellectuality and emotionality.

Singh (2013e) asserts that exemplary "collegial leaders use both lenses to inspire the best from their people and sustain high performance from individuals, teams and organizations" (p. 1616). Several studies indicate that EQ "is not in opposition to IQ, but it is an extension of the human's potential to succeed in a people-orientated environment" (Singh, 2013e, p. 1615; see also Goleman, 2004; Mayer \& Salovey, 1997; Stein \& Book, 2001). When "traditional cognitive intelligence (IQ) is combined with non-cognitive intelligence" (EQ), "leaders perform at their best and inspire their followers to be successful and happy" (Singh, 2013f, p. 335). It is affirmed by researchers such as Stein and Book (2001) and Goleman (1998) that EQ is not the antithesis of IQ, but rather, "it is a combination of both emotion and cognition" (Singh, 2013f, p. 335). EQ has increasingly become a vital part of how leaders currently meet the significant challenges they face (Childs, 2004; Singh, 2013b). Research indicates that the "culture of change in many organizations is rife with anxiety, stress and ambiguity and therefore, it should come as no surprise then that the most effective leaders are not the smartest in an IQ sense but are those who combine intellectual brilliance with emotional intelligence" (Singh, 2013e, p. 1615; see also Fullan, 2001). In 1980, as pointed out by Singh (2013e; see also Childs, 2004), "Reuven Bar-On investigated the qualities that led to success and he showed that there was much more than the traditional intelligence or IQ that was associated with an individual's success and Bar-On consequently developed the concept of Emotional Intelligence - the Emotional Quotient or EQ was born" (p. 1615).

According to Singh (2013f; see also Cherniss, 2000; Goleman, 2004; Singh, 2008, 2013c; Singh \& Manser, 2008), studies "in several organizations suggest that about two-thirds of the competencies linked to superior performance are emotional or social qualities such as self-confidence, flexibility, persistence, empathy, and the ability to get along with others. This research data further indicate that in leadership positions, ninety percent of the competencies necessary for success are social and emotional in nature" (p. 334). Singh (2013c; see also Merkowitz \& Earnest, 2006; Singh, 2013e, 2013f) affirms that healthy and "effective relationships, personal leadership, selfmanagement, personal growth and development, and recognition of potential problems are essential elements for creating a positive and a healthy working climate" (p. 490). It is therefore "impossible to construe leadership qualities without focusing on" EQ (Singh, 2013f, p. 334). As leaders work and learn from their experiences, their development of EQ traits can "empower them to manage their emotional responses to the challenges they face, ensuring that their feelings are expressed appropriately and effectively to foster collaborative relationships in their organizations" (Singh \& Dali, 2014, p. 1215). Failure to do so implies conditions become favourable for tobephobic leadership practices to prevail.

The process of human endeavour must be recognised as being as important as the task at hand and the product to be developed in organizations. Handy (1989) observed that clever organizations do not work in the ways that organizations used to work. These organizations "have shifted their emphasis from the management of tasks to the leadership of people; from control to collegiality" (Singh, 2013a, p. 959). Where bureaucratic management models focus on the importance of structure, authority, and top-down decision-making, post-bureaucratic models stress the importance of lateral relationships (Bush, 1993). Singh (2013a) states that the "decentralisation of power and the art of delegation are seen as key factors in increasing the efficiency of an organization" (p. 957). Emphasis should, therefore, be on the empowerment of employees and a commitment to shared decision-making (Dalin, 1994), rather than on power derived from hierarchical positions of line management structures.

The complexities of modern organizations in the twenty-first century require a new focus on leadership that extends beyond possessing cognitive abilities alone. In distinguishing between management and leadership, Kotter (2011) explains that management "is about coping with complexity" whereas leadership, "by contrast, is about coping with change" (p. 38). He confirms that, even though, each has its functions, both serve as distinctive and complementary systems that are necessary for success in complex and volatile business environments. According to Sterrett (2000), IQ, or general intelligence contributes no more than $25 \%$ to one's overall success as compared to the contribution made by one's EQ in the working environment. Even Goleman (2011) asserts that recent studies affirm that IQ and technical skills are not irrelevant seeing that they matter as "threshold capabilities" for entry-level 
requirements for executive positions (p. 1). However, he avers that these studies clearly indicate that EQ "is the sine qua non of leadership" (p. 1). In his analysis of competency models from 188 companies, Goleman (2011) supports his claim by pointing out that he found dramatic results that led him to the following conclusion:

Cognitive skills such as big-picture thinking and long-term vision were particularly important. But when I calculated the ratio of technical skills, IQ, and emotional intelligence as ingredients of excellent performance, emotional intelligence proved to be twice as important as the others for jobs at all levels. (p. 3)

Emotional dissonance traits (e.g. lack of empathy, poor communication skills) typical of TLs creates anxiety and tension amongst workers. The concept of TLs has its roots in the term tobephobia that encapsulates the fear of failure that can be experienced by any human being in any environment (Singh, 2010, 2011, 2013g). Its attribution to the fear of failure can imply several things (Singh, 2011, 2013g; Singh, Manser \& Dali, 2013; Singh \& Morar, 2009). For example, in the school situation, teachers' experiences of the fear of failure can be associated with their lack of professional competencies to cope with the constant changes that affect education (Singh, 2010, 2011, 2013g). In the workplace, employees can be subjected to tobephobic experiences because of the failure of leadership to address their anxieties and fears (Singh, 2013a, 2013f). In an article titled: Mismanaging unethical behaviour in the workplace, Singh and Twalo (2015b) draw attention to the concerns of workers when management failed to respond appropriately to misdemeanours and unethical behaviour of several of its employees, including managers. This fear of failure is compounded by the incompetence of indecisive leaders who do not adequately comprehend the emotional culture and climate of their organizations. These leaders can be guilty of getting work done through their subordinates by creating an environment that constantly creates tension and anxiety culminating in the fear of failure being experienced by their employees. Therefore, tobephobic experiences of employees in the workplace will be a key focus area in attempting to advance a theory of TLs.

\section{TOBEPHOBIC EXPERIENCES IN THE WORKPLACE}

As pointed out by Singh and Dali (2014; see also Alves, Manz, \& Butterfield, 2005), while "management is objectives-driven, resulting in stability based on rationality, bureaucratic means, and the fulfilment of contractual obligations", leadership is deemed to be purpose-driven, "resulting in change based on values, ideals, vision, symbols, and, most importantly, emotional exchanges" (p. 1215). This connotes that while the leaders coordinate, define a purpose, and anticipate, the essence of leadership is to teach and empower their employees to resolve conflict in a collegial manner (Singh \& Dali, 2014). Also, it affirms that leadership activity is not only restricted to practice "but also how that practice is framed by people's emotions, theoretical principles, and the contextual environment" (Singh \& Dali, 2014, p. 1215). Organizational change is one of the several potential sources of conflict that leaders can face in their organizations. As pointed out by Singh and Dali (2014; see also Cooper, 1984), one "of the sources of conflict is that employees are interested in traditional ways of doing their work because those ways have become part of them. Employees perceive things differently as a result of their prior experiences and expectations" (pp. 1215-1216). When there is a threat to an employee's status quo, then such employee who feels threatened will always be defensive and can create conflict within the organization. Changes would require much effort and adjustment by employees.

Autocratic bosses who believe in a win-lose approach can make life very unpleasant for their workers. Such bosses would "use all of the competitive weapons" they have to offer and they would expect the same from their employees and create the notion of the business world that it's a jungle out there (Miller, 1996, p. 1). The mantra of a leader lacking EQ skill would be: If you cannot stand the heat, get out of the kitchen. However, in a win-win situation, employers would show more compassion in their dealings with their employees and even their competitors. Admittedly, a collegial leader as a winner will see an answer to every problem, whereas a TL will see a problem in every answer (Miller, 1996). This distinction is made explicit by Miller when he argues that:

Controlling bosses who use the short leash approach to management are constantly frustrated by employees who refuse to be pushed and prodded. In contrast, bosses who use the long leash technique or empowerment tend to find a whole lot of dedicated employees who will follow them to the ends of the earth. (p. 63) 
TLs, who make maximum use of the short leash approach to management firmly believe that they must let their employees know who's the boss. In such a tobephobic workplace scenario, intimidation, humiliation, and fear are acceptable as organizational norms to get the work done coercively, and consequently deal a shattering blow to their employees' self-confidence and self-esteem. In contrast, the long leash approach of empowerment would not stifle teamwork, timeliness, decisiveness, innovation, openness and a sense of loyalty. This would create a culture of trust in the organization and employees are inspired with confidence and self-reliance, and are therefore provided with additional insight and energy to accomplish their tasks (Miller, 1996).

The lack of capacity development programmes to develop the work-integrated learning skills and knowledge of workers and their supervisors can impair the level of productivity in the organization (Singh \& Twalo, 2015b). When appointments are not made on the basis of whether the employees' knowledge is of an appropriate standard, then tobephobic reactions would emanate from employees who would not know precisely what is expected of them in their jobs (Singh \& Twalo, 2015a). A performance management system (PMS) is supposed to create a direct link between employee performance and organizational goals (Aguinis, 2005). It makes the workers' contributions to the organization explicit. A PMS that fails to make explicit employee contributions to the organization cannot be classified as a suitable PMS. Therefore, a poorly implemented PMS can have a devastating effect on the morale of workers when internal factors such as discrimination, unfair treatment of workers, and lack of recognition of excellence is evident in the organization (Singh \& Twalo, 2014, 2015a, 2015b). This can incite workers to engage in unethical behaviour because they do not feel attached, or even committed to the organization because a culture characterized by mistrust and poor interpersonal relationships between managers and their workers can be a breeding ground for unethical behaviour (Kaptein, 2011; Greenberg, 2002; Boye \& Jones, 1997; Hirschi, 1969). Mismanagement of employees' unethical behaviour implies that there are situations when managers and their employees are ignorant of the grave consequences of their behaviour, and consequently would be deprived of the opportunity to account for and alter their behaviour (Kaptein, 2011; Hollinger \& Clark, 1983). This can result in the concealment of the unethical behaviour, and the frequency of its occurrence without its detection because of poor management. Singh's research on tobephobic leadership (2013a, 2013b, 2013e, 2013g) reveals that a lack of collegial leadership in an organization can sow fear of failure amongst employees (Singh \& Twalo, 2015b). As argued by Singh and Twalo (2015b), when workers do not have the support of their leaders, then they are bound to justify their unethical behaviour. Singh (2014b; see also Filochowski, 2013) explains a possible cause of the fear of failure experienced by employees in the workplace:

If an organization is ignorant of what is intrinsically important, nothing is prioritised. The sheer number of demands on employees leads to despair and inaction, or frantic attempts being made to satisfy each demand by running a little way in one direction, and then turning. Giving employees work that they are not trained to do is a recipe for disaster in terms of organizational outputs. Such activity is fruitless and baseless and destroys the morale of the employees when they cannot do what they have been primarily employed for. It usually occurs when employees feel overwhelmed with too many things coming at them at too fast a pace. (p. 741)

The challenges of fear and anxiety amongst employees is further elucidated by Singh (2013b; see also Senge \& Kaufer, 2000; Chowdhury, 2000; Singh, 2008, 2011):

The challenges of fear and anxiety amongst employees arise because to some extent, everyone experiences fear of making a mistake, as all change efforts in the organization can induce fear. Deep change processes that call into question long-held beliefs and attitudes, and habitual ways of acting (such as deferring to the leaders, or leaders not having to reveal their reasoning), can be especially threatening to employees. Fear of failure in the organization can culminate in questions being raised by employees regarding their ability and training to perform at optimum levels and can be the cause of emotional dissonance in the workplace. This fear can result in them suffering from tobephobia that is associated with them being educationally inadequately equipped to do their work. Creating a fearful atmosphere in the working environment is a major management blunder that can impact negatively on the organization's vision and mission. (p. 802)

Singh (2013a) asserts that employees "need to feel comfortable in their capacity as decision-makers; they must not be manipulated by their line managers to experience fear of failure (tobephobia) because of being compelled to succumb to traditional bureaucratic management practices" (p. 960). Harford (2012) also points out 
unequivocally that it is "difficult to be unmoved by conditions in sweatshops" when the human factor becomes secondary to the product (p. 258).

The highly controlling, tough-guy boss is characterized by TLs who demonstrate the following traits (Singh, 2013a, 2013c, 2013d):

- Constantly, they demonstrate low levels of EQ and collegiality, and tend to be autocratic in making decisions.

- They do not firmly believe in inspiring or motivating other employees. Hence, there is little or even no encouragement given to their employees, and interpersonal contact with them is kept to a minimum.

- $\quad$ Such leaders are rather difficult to talk to, and they do not seem to listen or pay attention to their employees at all times. They are often preoccupied and, consequently, they are poor communicators.

- They are guilty of throwing tantrums in the workplace, and can therefore demonstrate bad-tempered attributes.

- $\quad$ They demonstrate little or no compassion and, therefore, often treat fellow workers shabbily.

- $\quad$ These leaders often experience difficulties in establishing healthy relationships in the workplace.

- $\quad$ These TLs do not overtly and willingly contribute to the happiness and job satisfaction of all their employees.

It is evident that "the research findings denote that a personal and emotional accountability system is essential for positive human development within the working environment. Unchecked emotional stress, ineffective and poor relationships, and personal stagnation can be costly in terms of human resource development. Honest selfassessment by leaders is requisite to positive and intentional personal change" (Singh, 2013e, p. 1622). Selfawareness, according to Singh (2013e; see also Goleman, 2004) "is an essential attribute of any leader seeing that it is the ability to recognize a feeling as it happens, to accurately perform self-assessments and have self-confidence. It is the keystone of emotional intelligence" (p. 1622). On the other hand, self-management or self-regulation, "is the leader's ability to keep disruptive emotions and impulses in check (self-control), maintain standards of honesty and integrity (trustworthiness), take responsibility for one's performance (conscientiousness), handle change (adaptability), and be comfortable with novel ideas and approaches (innovation)" (Singh, 2013e, p. 1622). Singh (2013e; see also Bliss, 2006) aptly states that motivation "is the emotional tendency guiding, or facilitating the attainment of goals shared by leaders with their followers" (p. 1622). This "consists of achievement drive (meeting a standard of excellence), commitment (alignment of goals with the group or organization), initiative (acting on opportunities), and optimism (persistence reaching goals despite setbacks). Leaders cannot function without empathy, seeing that it is the understanding of others by being aware of their needs, perspectives, feelings, concerns, and sensing the developmental needs of others" (Singh, 2013, p. 1622-1623; see also Goleman, 1998; Bliss, 2006; Kouzes \& Posner, 1997; Northouse 2004). A collegial work environment, therefore needs to be created for employees to be able to engage in self-criticism, self-planning, and self-problem-solving. All employees must be empowered to question traditional bureaucratic approaches in the workplace, and they must develop their workintegrated learning skills to emancipate themselves from conventional bureaucratic restrictive practices (Singh, 2013a, 2013e).

\section{LEADERS' TOBEPHOBIC INTELLECTUALITY}

Fear of failure "can have a dampening effect on employees' job satisfaction as it could negatively impact on their expectations and consequently, their self-esteem" (Singh, 2013b, p. 802; see also Singh, 2011). TLs prefer bureaucracy to collegiality, "and are usually founded on a yes-person culture around them. To them, power is enshrined in their position: it is a matter of positional authority instead of the authority of expertise identified amongst the employees" (Singh, 2013b, p, 802; see also Evans, 2000; Singh, 2010, 2013a). Much of the current leadership crisis in many organizations is based on the old-fashioned, top-down bureaucratic style of management (Singh, 2013a). The traditional emphasis on bureaucracy is being challenged by a normative preference for collegiality in many parts of the world (Manz \& Sims, 2001; Kouzes \& Posner, 1997; Kouzes \& Posner, 2001; Bush, 2003; Singh, 2008). According to Kouzes and Posner (1997), traditional management implies that the "ideal organization is orderly and stable, that the organizational process can and should be engineered so that things run like clockwork" (p. 15). As aptly pointed out by Kotter (2011), a central feature of modern organizations is 
interdependence, where no one has complete autonomy and where employees are frequently compared to their peers regarding their work, technology, management systems, and hierarchy. These linkages would inevitably present unique challenges when organizations must change in keeping with global trends. Traditional managers would, therefore, depend on the management functions of organizing, controlling and monitoring to create and ensure that human resource systems implement plans precisely and efficiently. On the other hand, collegiality is accepted to be "a collaborative process that entails the devolution of power to workers and other stakeholders in order for them to become an integral part of the leadership process of the organization and are guided by that organization's shared vision. Collegiality is therefore considered as a process of assimilation that involves encouraging personal visions to become part of a shared vision built on synergy" (Singh, 2013c, p. 489; see also Sergiovanni, 1991; Singh \& Manser, 2002; Singh, 2008, 2013f). Such a process is possible "because collegial strategies tend to be more lateral or more horizontal rather than being vertical and hierarchical, reflecting the view that all stakeholders should be involved in decision-making, and own the outcome of decisions" (Singh, 2013c, p. 490; see also Bush, 2003). Kouzes and Posner (1997) emphasize that leaders "know that no one does his or her best when feeling weak, incompetent, or alienated; they know that those who are expected to produce the results must feel a sense of ownership" (p. 12).

In contrast to collegial leaders, TLs "do not handle conflict well, will not ask for help and will not apologise if in the wrong" (Singh, 2013e, p. 1620). Sound relationships are minimal, and they do not seem "to be constantly concerned with others' problems. It seems as if they doubt the abilities of their employees and therefore constantly supervise them" (Singh, 2013e, p. 1620). Apparently, there is a mutual feeling of distrust between TLs and employees (Singh, 2013e). TLs do not seem to understand their workers' job satisfaction needs very well and, as a result, do not express empathy readily towards them. Singh (2013e) believes that such leaders lacking appropriate, emotionally intelligent behaviours:

...do not inspire confidence and cannot be relied upon to serve the best interests of the organization in the face of adversity. There are often examples of erratic behaviour and noticeable mood swings, and they are sometimes unpredictable and irrational. Clearly a collegial leader who demonstrates appropriate levels of emotionally intelligent behaviours will either create a functional collegial working environment or thrive in one. (p. 1620)

A non-existent collegial environment could suggest two scenarios that can be described as being opposite to a functional collegial workplace (Singh, 2013e):

The first one depicts a leadership structure that is largely autocratic. Accountability is not shared; leadership is regarded as a position of pre-ordained hierarchical power and the tobephobic leaders by choice hold themselves accountable for all that happens in their organizations. They determine the core values and their organizations' vision (if it exists), and the workers are told to abide by them. The focus is on getting the job done in the most efficient way possible, regardless of personal sacrifices that will need to be made. It is a cold, impersonal well-oiled machine. The second scenario depicts a sense of disarray and chaos in the organization. There is a very poor or non-existent work ethic. Workers are unsure of what the requirements of the organization are and have lost faith in their leader's ability to lead. There is a high rate of employee absenteeism; productivity is poor, and the organization is clearly rudderless. There are no core values in place; there is no vision for the organization and empowerment amplifies feelings of desperation to get things done by the few committed employees that may be present. (p. 1620)

Hence, the outcome of a poorly implemented PMS, according to Singh and Twalo (2015a), can result in poor management skills to resolve disputes and conflicts, blaming others for jobs not done well, and a lack "of trust between employer and their employees" (p. 89). Ineffectual leaders who lack the relevant competencies to manage their departments efficiently would be guilty of employing poor monitoring standards to evaluate their employees' work outputs. This would inevitably lead to the mismanagement of resources because of a lack of frequent job appraisal and feedback to employees (Singh \& Twalo, 2015b).

It is imperative that in order to achieve planned organizational objectives, leaders must "become peoplistic instead of being individualistic" (Singh, 2013b, p. 803; see also Chowdhury, 2000). Any organization can have the best communication system as a policy, "but if a leader is solely individualistic as a firm believer of bureaucratic 
measures, then the organization can suffer. Why? Communication can fail due to impregnable layers of bureaucracy" (Singh, 2013b, p. 803). It is obvious that "effective communication helps to break down traditional, organizational hierarchy, and it also encourages communication of good and bad news. Peoplistic communication must become a priority for the $21^{\text {st }}$ century emotionally intelligent leader if the happiness and job satisfaction of employees are to be part of the organization's vision, mission, and core values" (Singh, 2013b, p. 803; see also Chowdhury, 2000).

\section{LEADERS' TOBEPHOBIC EMOTIONALITY}

TLs demonstrate low levels of both EQ and collegiality and prefer being rational technocrats in managing their organizations. Such leaders can be prone to easily throw tantrums and can even be bad-tempered without empathizing with the needs of their employees (Singh, 2013e). As pointed out by Singh (2013e), TLs "do not show compassion and, therefore, treat their employees shabbily. These leaders tend to experience difficulties in establishing healthy relationships with their employees and have a limited preference for shared decision-making. Happiness and job satisfaction can become a challenge for employees to attain in such a non-existent collegial environment" (Singh, 2013e, p. 1623; see also Singh, 2013f). In a study focusing on a leadership development programme by Singh and Dali (2014), it was found that when the interpersonal work-integrated learning competencies of leaders are developed, then it can lead to them being empowered in creating a collegial climate so that their employees' feelings, needs, and concerns are not secondary to the objectives of the organization. They add that today, more than ever, leaders require appropriate work-integrated learning competencies in order "to process and manage emotional dynamics intelligently in the workplace" (Singh \& Dali, 2014, p. 1213). In contrast to TLs, leaders with a high EQ "are perceived to be happier and more committed to their organizations" because they can easily use their emotions to instill "a sense of enthusiasm, confidence, optimism, adaptability, empathy and collegiality" with their employees "through sound interpersonal relationships" (Singh \& Dali, 2014, p. 1214; see also Abraham, 2000; George, 2000). Therefore, in order to avoid tobephobic tendencies, leaders must be able to demonstrate emotional competencies that enable their employees to participate in shared decision-making without any fear of failure and subjugation. As asserted by Crawford (2007), it is not sufficient for leaders to merely acknowledge the inherent emotions in the culture of their organizations, they must make them explicit through their actions.

In Sterrett's (2000) K-A-B (Knowledge-Attitude-Behaviour) model, EQ is described in terms of two major dimensions: self and social. According to Sterrett, self-dimension comprises three areas: self-awareness (K), selfconfidence (A), and self-control (B). The social dimension of EQ in this model, as explained by her, reflects on one's experience and interactions with others in terms of empathy (K), motivation (A), and social competency (B). A lack of competencies in these six areas raises doubts about the leaders' EQ levels and their ability in dealing well with stress and anxiety and being adaptable. If leaders fail to inspire and motivate their employees, as well as fail to engender a collegial team spirit to achieve outstanding results, then a tobephobic environment of mistrust and fear of failure can ensue in which the workers will question the integrity of their leaders. TLs are leaders lacking EQ; their role in their organizations is therefore circumscribed by purely transactional relationships with their employees. Even human resources are reduced to the status of commodities!

\section{TOWARDS A THEORY OF TOBEPHOBIC LEADERS}

Studies clearly indicate that personal knowledge grows by tapping into a substantial body of existing knowledge that is supported by intensive and extensive research that generates theories (Parton, 2000; Singh, 2013a). Ornstein and Hunkins (2004) attest that good practice is based on theory, and according to them, practice means the procedures, methods, and skills that apply to the working world, where a person is on the job, or is actively involved in his or her profession. These "procedures and methods are teachable and can be applied in different situations" (Singh, 2013a, p. 954). For instance, when a theory such as the one on TLs "is applied in any organization, it should culminate in leaders and their employees" being able to identify the conflicting issues that are creating stressful working conditions and to address them appropriately (Singh, 2013a, p. 954). Such a process undoubtedly evokes the impact and importance of a theory on organizational practice as aptly pointed out by Kaplan (1964; see also Singh, 2013a): 
A theory is a way of making sense of a disturbing situation so as to allow us most effectively to bring to bear our repertoire of habits, and even more important, to modify habits or discard them altogether, replacing new ones as the situation demands. (p. 295)

Naturally, the question does arise whether a theory on TLs has the potential "to introduce leadership change in organizations" (Singh, 2013a, p. 953). Grundy (1987) asserts that theory "directs, confirms and legitimizes practice" (p. 51). According to Snow (1973), "a theory is essentially a symbolic construction that is designed to bring generalizable facts or laws into systematic connection" (p. 78). It becomes clear that action "in the realm of human affairs involves risks that can only be weighed up by the practitioners themselves seeing that action following from enlightenment must always be a matter of free choice" (Singh, 2013a, p. 953). Grundy (1987) affirms that:

Emancipation lies in the possibility of taking action autonomously. That action may be informed by certain theoretical insights, but it is not prescribed by them. (p. 113)

Several studies "suggest that theory includes the most advanced and valid knowledge available that can be generalized and applied to many situations in organizations seeking transformation, progress and a competitive edge within a global community" (Singh, 2013a, p. 954; see also Ornstein \& Hunkins, 2004). Singh (2013a; see also Coleman, 1994; Johnson \& Donaldson, 2007; Taba, 1962; Kouzes \& Posner, 2001) states that "any enterprise as complex as leadership requires some theoretical or conceptual framework of thinking to guide it" (p. 954). In order to study leadership activity, as asserted by Spillane, Halverson and Diamond (2004), it is insufficient to generate thick descriptions simply based on observations of what leaders do. They emphasize that: "We need to observe from within a conceptual framework if we are to understand the internal dynamics of leadership practice" (p. 4). They appropriately advocate that investigations of work practices require the development of new conceptual frameworks as these frameworks are built out of concepts that speak directly to practice (Singh, 2013a). A theory "can become more interesting and applicable when it becomes 'outside-in' rather than 'inside-out'. Theory drawn from the outside-in, rather than from a narrow view of inside-out, can provide guidance in shaping leadership practice in organizations" (Singh, 2013a, p. 954; see also Ornstein \& Hunkins, 2004; Bruner, 2001). An outside-in theory can facilitate a change in bureaucratic practices that can succumb to an inside-out approach (Singh, 2013a). Spillane, Halverson and Diamond (2004) assert that theoretical frameworks for studying leadership activity are insufficient and they strongly believe that we "need to observe from within a conceptual framework if we are to understand the internal dynamics of leadership practice" (p. 4). Parton (2000) concludes that rather than seeing the relationship in terms of the application of theory to practice, we must recognize that theory can be generative. Thus, Parton avows that:

Theory can offer new insights and perspectives such that practitioners can think and act differently. Ironically there is nothing as practical as a good theory. (p. 461)

When a theory "is applied in an organization, it should culminate in leaders and their employees being successful or effective" (Singh, 2013a, p. 953). Such a process evokes the significance of a theory of organizational practice as confirmed by Kaplan (1964):

A theory is a way of making sense of a disturbing situation so as to allow us most effectively to bring to bear our repertoire of habits, and even more important, to modify habits or discard them altogether, replacing new ones as the situation demands. (p. 295)

Hence, an effective and efficient working community is organized in such a way that it fosters an open flow of thoughts amongst workers, which also includes the upper echelons of management and leadership; "stimulates critical reflection about analyses of ideas, policies, problems, and solutions; creates notions of what is universally acceptable as being the common good; and develops a concern for the rights and dignity of all workers" (Singh, 2013f, p. 331; see also Kochan \& Reed, 2005; Short, 1998; Retallick \& Fink, 2002). In such a setting, it is expected that "employers and employees would function together using democratic principles to improve organizational effectiveness" (Singh, 2013f, p. 331). Participation would build self-confidence, loyalty, and motivation as this would empower employees when they are part of the solution (Sterrett, 2000). When TLs fail to permit their 
employees to participate fully in shaping their future, resistance to change will be greater by employees and this will manifest in them demonstrating greater levels of antagonism with the result being lower productivity (Sterrett, 2000). Trust building by high EQ leaders is deemed to be an imperative, whether the news is good or bad. Such collegial leaders would rope in all their employees in the decision-making process, as accountability would be shared by the group as a team. Fullan (2007) appropriately points out that:

The litmus test of all leadership is whether it mobilizes people's commitment to putting their energy into actions designed to improve things. It is individual commitment, but, above all, it is collective mobilization. (p. 9)

The leaders' behaviour towards their workers can influence their emotions in either a positive or negative way, as situations, moods and events created, offer opportunity for emotional responses from employees (Singh, Manser \& Dali, 2013). It is generally expected of leaders to wear many hats and consequently assume several roles, and depending on the situation that they would find themselves in, they could be leaders or subordinates, depending on the circumstances that prevail in their organizations (Kochan \& Reed, 2005; Singh, 2005; Thilo, 2004; Kouzes \& Posner, 1997). Expectedly, being "a leader requires the person to promote an organizational passion for quality. It is a myth that leaders are entrusted with the absolute power to manage all the resources of the organization" (Singh, 2013c, p. 499). The heart of collegiality is, therefore, to have shared decision-making as a norm for cementing relationships in the organization. TLs deceptively believe that they can get extraordinary things accomplished entirely by themselves. However, research accomplished by Kouzes and Posner (2012) contradicts this perception by clearly pointing out that:

Leaders mobilize others to want to struggle for shared aspirations, and this means that, fundamentally, leadership is a relationship. Leadership is a relationship between those who aspire to lead and those who choose to follow. It's the quality of this relationship that matters most when engaged in getting extraordinary things done. (p. 30)

Hence, research studies cited in this paper clearly allude to two dimensions of a tobephobic leadership theory: tobephobic intellectuality and tobephobic emotionality. These two dimensions can be broken down further into six components for each dimension comprising competencies, motivation, satisfaction, decision-making, empowerment, and relationships as are depicted in Figure 1. The tendencies of a TL are succinctly presented in Figure 1. Admittedly, it is impossible to list all the possible tendencies that can be demonstrated by TLs in this paper. Further research on TLs is required to expand the list of tendencies demonstrated by these leaders. 


\begin{tabular}{|c|c|c|}
\hline & Tobephobic Intellectuality & Tobephobic Emotionality \\
\hline Competencies & $\begin{array}{ll}\text { - } & \text { Autocratic, technocratic and rationalistic } \\
\text { - } & \text { Favours a command style of management } \\
\text { - } & \text { Concentrates on technical skills } \\
\text { - } & \text { Not prepared to take risks } \\
\text { - } & \text { Adheres to traditional bureaucratic } \\
\text { - } & \text { Wanagement practices } \\
\text { - } & \text { Goals and expectations not clearly spelled } \\
\text { - } & \text { Lut } \\
& \text { Lack negotiation skills }\end{array}$ & $\begin{array}{ll}\text { - } & \text { Lack social and personal skills } \\
\text { - } & \text { Lacks fairness and objectivity } \\
\text { - } & \text { Does not adapt easily to change } \\
\text { - } & \text { Limited communication and conflict } \\
\text { - } & \text { management skills } \\
\text { - } & \text { Useor self-awareness skills } \\
\text { - } & \text { Not easy to talk to } \\
\text { - } & \text { Not prepared to listen to alternative options } \\
\text { - } & \text { Gives preference to convergent responses } \\
\text { from employees }\end{array}$ \\
\hline Motivation & $\begin{array}{ll}\text { - } & \text { Blames others for failures } \\
\text { - } & \text { Sets goals that are impossibly high } \\
\text { - } & \text { Sets goals that are insultingly low } \\
\text { - } & \text { Fails to inspire, motivate and encourage } \\
\text { - } & \text { Gives limited attention to the Individual } \\
\text { - } & \text { needs of workers } \\
\text { - } & \text { Limits not take the initiative to determine } \\
\text { others' needs }\end{array}$ & $\begin{array}{ll}\text { - } & \text { Lacks sensitivity } \\
\text { - } & \text { Shows pessimism in the face of failure } \\
\text { - } & \text { achievement } \\
\text { Limited development opportunities for } \\
\text { - } & \text { Sorkers } \\
\text { - } & \text { Does not exude confidence } \\
\text { - } & \text { Outlook is not inspiring } \\
\text { - } & \text { Is not a calming influence } \\
\text { - } & \text { Not always accessible and supportive } \\
\text { - } & \text { Does not frequently and overtly express } \\
& \text { appreciation } \\
\end{array}$ \\
\hline Satisfaction & $\begin{array}{ll}\text { - } & \text { Productivity based solely on output model } \\
\text { - } & \text { Prefers neutrality instead of solving problems } \\
\text { jointly } \\
\text { - } & \text { Prefers to be evasive } \\
\text { - } & \text { Uses punitive measures without hesitation } \\
\text { - } & \text { Creates limited opportunities for shared } \\
\text { decision-making }\end{array}$ & $\begin{array}{ll}\text { - } & \text { Stressful workplace } \\
\text { - } & \text { Creates mistrust and unhappiness } \\
\text { - } & \text { Doeks calmness when under pressure } \\
\text { - } & \text { Creates resentment by having favourites } \\
\text { - } & \text { Contributes to poor morale amongst workers } \\
\text { - } & \text { Is evasive of emotional truths } \\
\text { - } & \text { Fails to inspire, motivate and encourage } \\
\text { - } & \text { Creates doubts, anxiety and stress } \\
\text { - } & \text { Has a threatening demeanour } \\
\text { - } & \text { Does not easily apologise and admit faults } \\
& \text { Adopts mediation processes that lack fairness } \\
\end{array}$ \\
\hline Decision-making & $\begin{array}{l}\text { - Depends on "my" approach to get things } \\
\text { done, which is based on positional authority: } \\
\text { top-down, hierarchical } \\
\text { - Creates limited opportunities for shared } \\
\text { decision-making } \\
\text { - Makes decisions themselves during conflicts } \\
\text { - Likes being autocratic and rationalistic } \\
\text { - Prefers centralization and staff dependency } \\
\text { and accountability is not shared }\end{array}$ & $\begin{array}{ll}\text { - } & \text { Questions decisions based on one's } \\
\text { - } & \text { Lacks empations, even if it benefits the organization } \\
\text { - } & \text { Controls initiative of subordinates } \\
\text { - } & \text { Not easily prepared to listen to alternative } \\
\text { options } \\
\text { - Does not readily promote workers' right to } \\
\text { self-regulation } \\
\text { Is dominating and intimidating and lacks } \\
\text { humanistic traits }\end{array}$ \\
\hline Empowerment & 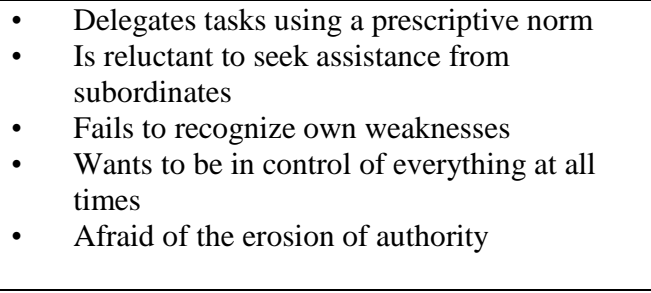 & $\begin{array}{ll}\text { - } & \text { Prefers centralization } \\
\text { - } & \text { Can be threatening and demanding } \\
\text { - } & \text { Does not celebrate others' success freely } \\
\text { - } & \text { Easily shifts blame to others } \\
\text { - } & \text { Punishes failure with impunity } \\
\text { - } & \text { Abhors risk-taking } \\
\text { - } & \text { Firmly believes in positional authority } \\
\end{array}$ \\
\hline
\end{tabular}

Figure 1. Lamentable Tendencies of a Tobephobic Leader 


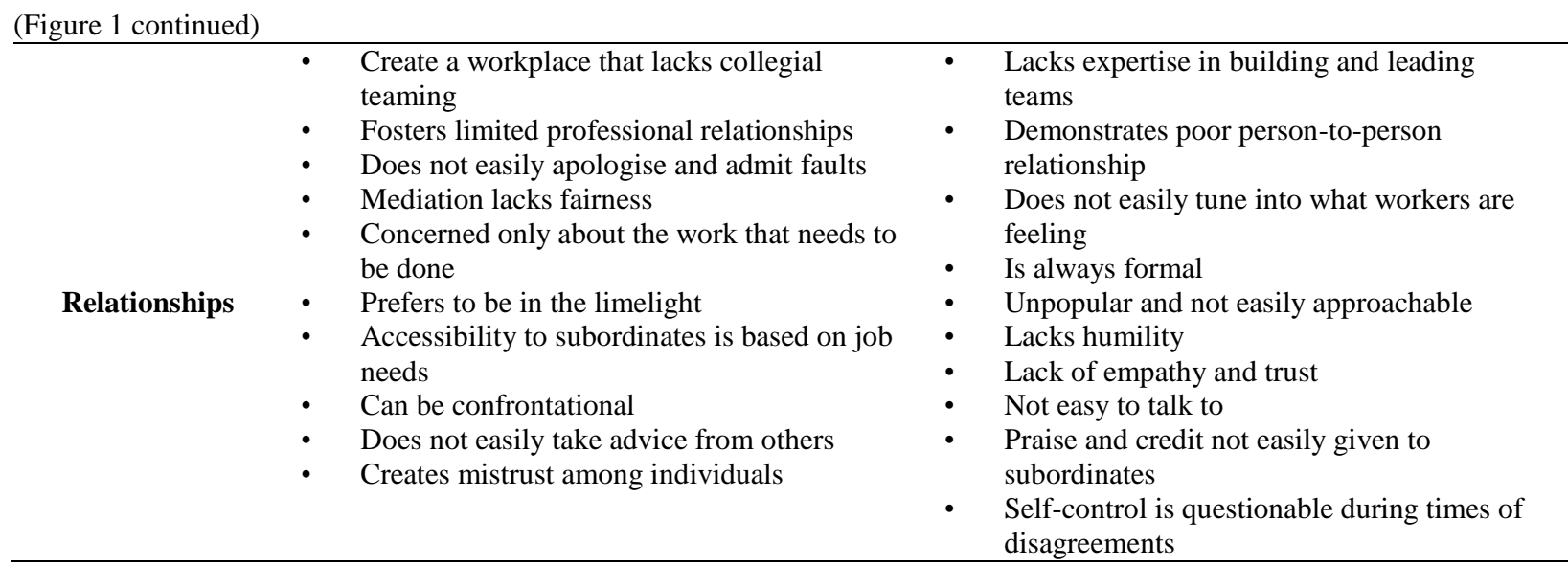

\section{Competencies}

Leaders who are not prepared to take risks and adhere strictly to traditional bureaucratic management practices clearly demonstrate TL traits. Such leaders are technocrats who create a working environment that is not tension free. They do not have an open-door policy and hence, because of limited communication with their workers, relationships are established on a top-down hierarchical approach. Such leaders largely depend on their technical and rational skills to make decisions, implement their plans and evaluate the outputs of their workers. Collegiality in decision-making is a rarity, raising doubts of whether the vision of the organization is shared by all its employees. Vision is defined by Coleman (2003) as "a desirable future state of the organization" (p. 158). This vision must "be inspirational so that the members of the organization are motivated to work towards it with pride and enthusiasm" (Singh, 2013a, p. 959). When "organizational members perceive the vision as their own, they will feel internally driven to achieve the organizational objectives dictated by the vision" (Singh, 2013a, p. 959). Conger and Kanungo (1998; see also Singh 2013a) point out that a sense of powerlessness will be created amongst employees when leaders install "structures and mechanisms that foster a sense of control over the resources needed to perform meaningful tasks required for the vision's accomplishment" (p. 196).

Kouzes and Posner (2012) justly assert that one of the five practices of exemplary leadership is for leaders to model the way. By doing so, these leaders need to clarify values by finding their voice and affirming shared values in their organizations. Therefore, to achieve this noble goal of collegiality rather than tobephobic leadership practices, such collegial leaders have to set the example by aligning actions and shared values with their employees. Social skills such as empathy and trust are of paramount importance for collegial leaders. When there is distrust amongst workers in the workplace, values will become vague and blurred.

\section{Motivation}

Control, as pointed out by Singh (2014a), "is so central to bureaucratic management practices that highly motivated or inspired behaviour of employees is almost irrelevant" (p. 57). Kotter (2011) asserts that:

Managerial processes must be as close as possible to fail-safe and risk-free. That means they cannot be dependent on the unusual or hard to obtain. The whole purpose of systems and structures is to help normal people who behave in normal ways to complete routine jobs successfully, day after day. (p. 49)

Kotter clarifies why leadership is different, as follows:

Achieving grand visions always requires a burst of energy. Motivation and inspiration energize people, not by pushing them in the right direction as control mechanisms do, but by satisfying basic human needs for achievement, a sense of belonging, recognition, self-esteem, a feeling of control over one's life, and the ability to live up to one's ideals. (p. 49) 
Evidently, when "a leader supports the development of a collegial organization environment that advocates shared leadership", then the leader's EQ "is an important contributor to the attainment of such an environment" (Singh, 2013c, p. 493; see also Gardiner \& Stough, 2002). A possible way to cater for the needs of employees is "the creation of enriched jobs that are seen to help create self-motivated workers who love their jobs" (Singh, 2013c, p. 493; see also Landy, 1985). McGregor's theory X and theory Y emphasises the "need to view all employees in a positive light (theory Y) rather than from a negative perspective (theory X)" (Singh, 2013c, p. 493; see also Middlewood, 2003). A collegial environment, therefore, "plays a crucial role in the improvement of efficiency and effectiveness in organizations as decisions that are imposed, rather than attained through a process of consensus, could be regarded as unethical and could therefore demotivate workers who do not support the decisions made. This could result in an organization becoming less efficient, less effective and, therefore, less productive" (Singh, 2013c, p. 493; see also Williams, 1989; Singh, 2005, 2008). Obviously, leaders "cannot simply succeed through intellectual arrogance" (Singh, 2013b, p. 801; see also Levine, 2000). Leadership is all about people and, according to Codianni, as quoted by Kouzes and Posner (2012), "Encouraging the heart is the most important leadership practice because it's the most personal" (p. 29). Singh (2013b) asserts that employees' "emotions do matter, and if they are ignored by leaders, then quality performances will diminish. Emotional truths can be marginalized and blocked out" by TLs (p. 801).

The following guidelines for action are provided by Singh (2013g; see also Pfeffer \& Sutton, 2000) to drive out fear in organizations during hard times:

- $\quad$ Prediction: Give employees as much information as possible about what will happen to them and when it will happen.

- Understanding: Give employees detailed information about why actions, especially actions that upset and harm them, were taken.

- $\quad$ Control: Give employees as much influence as possible over what happens, when things happen, and the way things happen to them; let them make as many decisions about their fate as possible.

- $\quad$ Compassion: Convey sympathy and concern for the disruption, emotional distress, and financial burdens that people face. (p. 696)

\section{Satisfaction}

Leaders need to inspire a shared vision in their organizations, as strongly suggested by Kouzes and Posner (2012). To succeed in achieving this, leaders must search for opportunities by seizing the initiative and looking forward to innovative ways to improve. They need to experiment and take risks so that they learn from their experiences, no matter how big or small their win is. This is what distinguishes the collegial leader from the TL; self-confidence and self-awareness contribute to their emotionally intelligent behaviours as opposed to TLs who tend to be indecisive and reluctant to take the initiative to experiment and take risks. Credibility is the foundation of what makes collegial leaders to succeed in contributing to the job satisfaction of their employees because such leaders' word can be trusted because they are well endowed with the skill, knowledge, attitude, and values to lead (Kouzes \& Posner, 2012). On the behaviour of leaders, Singh (2013e) asserts that:

To merely understand or expect a certain type of behaviour from one's leader may do little to improve one's feeling of job satisfaction. The behaviours, although predictable, may be inappropriate, and the inappropriateness of the leader's behaviour may create a sense of dissatisfaction. A leader's predictable, but the inappropriate behaviour may be debilitating and more restrictive rather than beneficial. Employees may be fearful and feel demotivated and dissatisfied if their leader's predictable behaviour is often perceived as being inappropriate. (p. 1621)

It is important that employees not be constantly put into job situations that they cannot cope with, as this would inevitably increase their stress levels. In order to manage stress, employees must openly admit their stress status to their employers so that the symptoms could be identified and addressed. It is essential to have open communication in the workplace as this would build trust and commitment, and get the support these employees need to overcome the stigma around depression and anxiety (The Standard, 2014). It is, therefore, imperative to allow sufficient time to listen to as many people and draw on as many information sources as possible in order to have a sustainable performance system in the organization (Singh \& Twalo, 2015a). An effective performance 
management requires effective management, a key component of which is building relationships across organizational boundaries (Singh \& Twalo, 2015a; Holloway, 2009; Aguinis, 2005; Armstrong, 2006). The financial reporting disasters of many organizations such as Enron and Sunbeam provide ample evidence of what can happen when the figures are distorted to get better results (Castellano, Young \& Roehm, 2004). In the midst of these devastating failures, very little attention has been paid to the enormous pressure that can occur when an organization's PMS is used to align and motivate employee behaviour. As pointed out by Singh and Twalo (2015a), what "is questionable is the continued usage of stretch targets and benchmarking, as such targets can lead to distortion of the system and the figures, as fearful workers would try to achieve the numerical goal, even though, this was beyond their capabilities" (p. 83). In any organization, "the creation of opportunity cannot flourish in a climate of negativity" and, therefore, a leader's optimism should form the "nucleus of a positive collaborative climate and a collegial environment where a sense of job satisfaction amongst workers is enhanced" (Singh, 2013c, p. 490; see also Millinger, 2004).

\section{Decision-making}

TLs demonstrate low levels of EI and collegiality and are autocratic as well as tobephobic in decisionmaking, are prone to tantrums and can be bad-tempered (Singh, 2013b, 2013e). Such leaders show no compassion and, therefore, treat fellow workers shabbily and create fear in the work environment (Singh, 2010, 2013b). When TLs are justly questioned by concerned employees on work-related issues linked to a PMS, then they are labelled as being confrontational. Low emotionally intelligent behaviours by leaders can impact negatively on employees' performance delivery and cause dissatisfaction in the workplace (Pascoe, Ali \& Warne, 2002; Shoho, Merchant \& Lugg, 2005). These are the traits often demonstrated by TLs who (Goleman, 1998, p. 287):

- $\quad$ Make decisions that demoralize;

- $\quad$ Have difficulty managing creativity and making decisions;

- $\quad$ Ignore the crucial value of social skills;

- $\quad$ Display an inability to motivate and inspire;

- $\quad$ Create hollow mission statements;

- $\quad$ Display empty slogans of the day;

- $\quad$ Follow leadership by the book;

- $\quad$ Lack zest or energy;

- Demonstrate drudgery instead of spontaneity;

- $\quad$ Have a lack of esprit de corps;

- Ignore teams that don't work.

In order to address the concerns about TL traits, Singh (2013b; see also Evans, 2000; Vermeulen, 1999; Liddy, 2013; Levine, 2000) points out that:

At the heart of leadership is the ability to set goals and directions with a vision that is also owned by every employee in the organization. Leaders need to be sensitive to the need for change on the one hand and empathise with how employees feel about what they are expected to do on the other. There is a dire need to have an understanding of emotional grammar and an ability to identify emotions in employees and themselves as leaders. A high staff turnover is experienced in organisations where leaders convey negative feelings to their staff as their sense of meaningful collaboration and sincere community identity are in doubt and hence, they are not trusted by the workforce. (p. 802)

Research undertaken on power, control, and accountability in organizations such as schools indicates that "it makes no sense to hold people accountable for something they do not control or to give people control over something for which they are not held accountable" (Singh, 2013a, p. 957). Accountability "without commensurate power is unfair and can be harmful. Likewise, giving employees simply more power alone is not the answer" seeing that "experts in organizational management and leadership have long held that accountability and power must go hand in hand in workplaces and that increases in one must be accompanied by increases in the other" (Singh, 2013a, p. 957; see also Ingersoll, 2007). Changes "in both accountability and power are necessary to accomplish the larger systemic goal" in order to ensure that employees experience job satisfaction in an environment free from the 
tobephobic effects of bureaucratic practices (Singh, 2013a, p. 957; see also Ingersoll, 2007). The empowerment "of employees in any organization depends on the devolution of power by leaders" (Singh, 2013a, p. 955). TLs "cling to power as an entitlement of their bureaucratic positions. In contrast, collegial leaders share their power base in order to flatten hierarchies. Empowered employees demonstrate a greater commitment to complete a task based on their increased sense of self-confidence, self-determination and personal effectiveness" (Singh, 2005, 2013a, p. 955; see also Kouzes \& Posner, 2012; Singh, 2005, 2008).

Superior results over a sustained period are the hallmarks of leaders who espouse collegiality in creating maximum opportunities for all their employees (Singh, 2014a). In a study of transformational collegial leadership (Singh, 2014a), the following characteristics of TLs were present in organizations lacking collegial approaches in managing human resources:

- $\quad$ Closed-door policy which failed to invite all people to show their expression by freely participating in a participatory democratic process;

- $\quad$ Lack of opportunities for everyone to take an active part in the formal processes and commitment, belief and trust in the democratic process;

- $\quad$ Lack of recognition for individual expertise to take on responsibilities.

Collegiality "emphasizes the valuing of individuals where there is a breadth of leadership and an absence of hierarchy and a belief in the democratic process" (Singh, 2014a, p. 59).

\section{Empowerment}

Studies indicate that to focus merely on the bureaucratic practices "of positional leaders to get the job done is problematic since research underscores the dire need to move beyond those at the top of organizations in order to understand collegial leadership" (Singh, 2013a, p. 958; see also Singh, 2005, 2008). Bureaucratic management models "focus on the importance of structure, authority, and top-down decision-making," whereas "postbureaucratic models stress the importance of lateral relationships" (Singh, 2013a, p. 957; see also Bush, 1993). Empowerment "flows from the recognition that the cultural world, unlike the natural world, is a human construction and, hence, is capable of being recreated. Post-bureaucratic management thinking, therefore, encourages leaders to adapt a transformational leadership policy" (Singh, 2013a; see also Grundy, 1987). Empowerment and shared decision-making is explained by Singh (2013a; see also Cyert \& March, 1963; Goleman, Boyatzis, \& McKee, 2002; March \& Olsen, 1984; Spillane et al., 2004) as follows:

If empowerment has taken place and individuals, interest groups and institutions are given the opportunity to accept responsibility, they will then need to be accountable for the decisions that are made. With empowerment comes accountability and in a collegial leadership model, the concept of shared decision-making. This suggests that those who form part of a shared decision-making process are responsible and accountable for the way they lead the organization. Thus, critics of the solo decision-maker model have argued for giving attention to the shifting coalitions of decision-makers in organizations in which preferences and coalition membership are neither stable nor unified. Strong relationships are employees' most powerful leadership asset. (p. 958)

It is clear that "collegiality is a collaborative process that entails the devolution of power to employees in order for them to become an integral part of the leadership process of the organization's shared vision" (Singh, 2013e, p. 1615; see also Cherniss, 2000). George, Sims, McLean and Mayer (2011; see also Singh, 2014a) evoke the essence of empowering employees by stating that:

Authentic leaders recognize that leadership is not about their success or about getting loyal subordinates to follow them. They know the key to a successful organization is having empowered leaders at all levels, including those who have no direct reports. They not only inspire those around them, they empower those individuals to step up and lead. (p. 176)

TLs create uncertainty in the minds of their employee leaders by raising trivial, unsubstantiated and biased questions about their achievements. They feel threatened when employees' achievements outshine theirs (TLs). They 
selectively disseminate information in the workplace in an attempt to create uncertainty in the workplace in order to cement their authority, even though they may lack the expertise to do so. TLs fear being outshone by their subordinates.

Leaders must have the skills to understand empathetically what the fears and needs of their employees are "and where their strengths and weaknesses lie" (Singh, 2013b, p. 803; see also Stein \& Book, 2001). These leaders need to fully understand that their workers "display a variety of emotions that should be handled with professional sensitivity" (Singh, 2013b, p. 803). Both social and personal emotionally intelligent behaviours must "be put into practice in order to improve the leaders' ability to handle ever-changing situations, and they should be flexible to choose a suitable behaviour for the appropriate situation" (Singh, 2013b, p. 803). As pointed out by Singh (2013b; see also Du Plessis, Bouwer \& Eloff, 2002):

When leadership structures are built around the empowerment of individuals and the active involvement of all employees, the best long-term efficiency is achieved. Most employees want to feel confident in their jobs and know that by being empowered, they are making meaningful contributions to the effectiveness of their organizations Empathy and compassion are the nucleus of collaboration and empowerment, because without them human feelings and emotions are ignored and employees then begin to stray from the organization's core purpose because they are unhappy. (p. 803)

Cooper and Sawaf (1997) also emphasise the importance of relationships in organizations:

It is from empathy, especially when there is an environment of trust, that connection comes, one person to another. In terms of corporate and career achievements, it can be said that almost everything begins and ends in the emotions of confident relationships, in human connectedness. (p. 53)

Recent studies "confirm that collegial leadership not only involves leadership behaviours that build willing followers who commit themselves to the organization's objectives, but it also empowers followers to accomplish these objectives by their becoming leaders in their fields of expertise (Singh, 2013e, p. 1617; see also Kouzes \& Posner, 1997; Yukl, 1998; Goleman, 1996; Singh, 2013b). TLs fail to command the trust of their followers because these leaders more often than not, simply focus on their needs. To empower employees "is an important aspect in establishing emotionally intelligent collaboration, as the willing and satisfied participation of the employees can be the result of leaders' commitment to establishing a collegial working environment" (Singh, 2013e, pp. 1617-1618; see also Manser, 2005; Singh, 2013c; Singh, Manser \& Dali, 2013). When employees trust their leaders as well as each other, then they are more likely to fan the success flames of their organizations. Kouzes and Posner (2012) aptly state that:

Constituents neither perform at their best nor stick around for very long if you make them feel weak, dependent or alienated. Giving your power away and fostering their personal power and ownership will make them stronger and more capable. When you strengthen others by increasing self-determination and developing competence, they are likely to give it their all and exceed their own expectations. (p. 22)

\section{Relationships}

Leadership is a relationship between employers and their employees. Strengthening of this relationship is crucial to the success of all organizations since reciprocity is a basic requirement for this to materialize. When this relationship stumbles, the human resource income will drop concomitantly with the financial income. Employees are greater assets to their organizations than simply the merchandises of daily transactions between the business organizations and their customers. Without the productivity of their human resources, the financial deficits of the organization will become a reality to the detriment of the continued existence of the organization. Kouzes and Posner (2012) state that leaders "never get extraordinary things accomplished all by themselves" (p. 30). They assert that:

Leadership is a relationship between those who aspire to lead and those who choose to follow. It's the quality of this relationship that matters most when engaged in getting extraordinary things done. A leader - constituent 
relationship that's characterized by fear and distrust will never produce anything of lasting value. A relationship characterized by mutual respect and confidence will overcome the greatest adversities and leave a legacy of significance. (p. 30)

A high staff turnover is usually "experienced in institutions where leaders convey negative feelings to their staff as their sense of meaningful collaboration, and sincere community identity were questioned. Workers need to feel that they can make a meaningful input as individuals and at the same time help create a common goal for their organizations in general without fear of reprisal from their leaders" (Singh, 2013c, pp. 492-493; see also Singh \& Manser, 2002, 2008; Northouse, 2004). According to Goleman (1998), leadership must be collaborative and transformational in an emotionally intelligent organization:

The interpersonal skills and compatibility of the group members emerged as key to their performance. When teams operate at their best they can be more than simply additive - they can be multiplied. In other words, the best talents of one person catalyse the best of another and another... for when a team has synergy its score far outweighs the best individual score. (p. 205)

Depending on the nature of the relationship between the leaders' EQ and shared leadership in the organization (Singh, 2013c), Gardiner and Stough (2002) allude to a strong relationship between the high EQ of leaders and the strength of leadership in the organization. Gardiner and Stough (2002; see also Singh, 2013c) emphasize the importance of the EQ of leaders in managing and monitoring their emotions:

The ability to manage and monitor emotions within oneself and others correlated with the inspirational motivation and individualized consideration components of transformational leadership. Second the ability to monitor emotions within oneself and others correlated significantly with the transformational leadership components of idealised attributes and idealised behaviours. (p. 71).

Sterrett (2000) affirms that:

It is EQ that helps us establish relationships and become politically savvy in the office, and it is what keeps us going in difficult times. If you think business is or should be based only on rational skills, the newest research would urge you to rethink this notion: Emotional Intelligence is the most fundamental dimension of leadership today and in the foreseeable future, and the higher we aspire to or rise in leadership positions, the more important it becomes. (p. 5)

Leaders are normally "expected to develop their empathic capacity so that their employees' needs and concerns are understood. Empathy serves as a gateway to understanding and compassion and therefore emotionally intelligent leaders would not plow through and impose their agenda, leaving their employees demoralized and angry" (Singh, 2013b, p. 803; see also Birchfield, 2013). Singh (2013b; see also Singh, Manser \& Dali, 2013) avers that:

A 21 st century organization should be characterized by collaborative teamwork practices because it should have shifted its emphasis from the management of tasks to the leadership of people. This view is supported when one accepts that leadership involves the creation of multi-partnerships, the success of which is embedded in the quality of relationships that function as inclusive, motivated units. In order for the collaborative units being functional, people need to be led with confidence and leaders need to have a clear understanding of the needs and the emotional strengths and weaknesses of those who are to be led. (p. 803)

Evidently, emotional truths can "translate into trust and create a sense of belongingness, depending on the leaders' ability to identify their emotions and those of their employees" (Singh, 2013b, p. 801; see also Levine, 2000). Bouchikhi and Kimberly (2000, p. 217) state that that after being pushed to the background by the logic of scientific management, "the centrality of trust in organizational life is being rediscovered" (Singh, 2013b, p. 801). The "challenges of management and leadership in the $21^{\text {st }}$ century will require that trust be put at the core of the employment relationship" (Singh, 2013b, p. 801). 


\section{CONCLUSION}

The focus of this article is to advance a theory of TLs because no such attempt has yet been made globally. Admittedly, research on leadership as presented in this article, alludes to the importance of EQ as a component of leadership skills. Leaders lacking EQ can be labelled as being tobephobic in their approach to employer-employee relationships. Specifically, this tobephobic perspective has received scant attention to the role of EQ in leadership practice. The tobephobic perspective goes beyond the basic EQ skills requirement that leaders are essentially required to demonstrate in the workplace; the theory of tobephobic leadership introduces a new dimension in how we can view extreme bureaucratic or autocratic practices in any organization. Linking it to the fear of failure evokes the powerful notion of emotionality as being of equal importance to one's intellectuality. This is a reality in organizations that discounts the value of its human resources. The conceptual framework on TLs provided in this article closes, to some extent, the blind and blank spots in research on leadership activities. Therefore, the primary objective of this article is to expand the notions of leadership that are currently in practice in organizations. Such a theory could make a major impact on how we view leadership practices in different organizations and could, therefore, make a significant contribution to our understanding of leadership activities. Hopefully, this article will serve as a springboard for future critical research and discussion of the myths and realities of having TLs in organizations.

\section{AUTHOR INFORMATION}

Prakash Singh is a professor of education at the Nelson Mandela Metropolitan University in Port Elizabeth, South Africa. He is currently a rated researcher by the National Research Foundation in South Africa, and is a former Senior Research Fulbright scholar. Professor Singh is the author of Innovative Strategies to Develop Better Schools and co-author of Principal Leadership. He has also published widely in peer-reviewed journals, focusing on collegial leadership, traditional bureaucratic management practices, organizational effectiveness, emotional intelligence, tobephobia, and self-regulated learning. Professor Singh has presented numerous papers at international conferences. E-mail: Prakash.Singh@nmmu.ac.za

\section{REFERENCES}

Abraham, R. (2000). The role of job control as a moderator of emotional dissonance and emotional intelligence: Outcomes relationships. The Journal of Psychology, 134: 169-189.

Aguinis, H. (2005). Performance management. Edinburgh: Heriot-Watt University.

Alves, J.C., Manz, C.C., \& Butterfield, D.A. (2005). Developing leadership theory in Asia: The role of Chinese philosophy. International Journal of Leadership Studies, 1(1): 3-27.

Armstrong, M. (2006). Performance management: Key strategies and practical guidelines. London: Kogan Page.

Birchfield, J. (2013). Empathy: A gateway to objectivity in leadership. Retrieved from: http://www.huffingtonpost.com/jan-birchfield-phd/empathy-business_b_2804056.html.

Bliss, S.E. (2006). The effect of emotional intelligence on a modern organizational leader's ability to make effective decisions. Retrieved from: http://eqi.org/mgtpaper.htm

Bouchikhi, H., \& Kimberly, J.H. (2000). The customized workplace. In S. Chowdhury (Ed.), Management $21 C$. London: Prentice Hall.

Boye, M. W., \& Jones, J. W. (1997). Organizational culture and employee productivity. In R.A. Giacalone, \& J. Greenberg (Eds.), Antisocial Behavior in Organizations. Thousand Oaks, CA: SAGE.

Bruner, J. (2001). The culture of education. Cambridge, Mass.: Harvard University Press.

Bush, T. (1993). Exploring collegiality: theory, process and structure in managing schools. Milton Keynes: The Open University.

Bush, T. (2003). Organisational structure. In M. Thurlow, T. Bush \& M. Coleman (Eds.), Leadership and strategic management in South African schools. London: Commonwealth Secretariat.

Caruso, D., \& Salovey, P. (2003). The emotionally intelligent manager. San Fransisco: Jossey-Bass.

Castellano, J.F., Young, S., \& Roehm, H.A. (2004). The seven fatal flaws of performance management. The CPA Journal, 74(6): 32-35. Retrieved from: http://www.nysscpa.org/cpajournal/2004/604/essentials/p32.htm

Cherniss, C. (2000). Social and emotional competence in the workplace. In R. Bar-On \& J.D.A. Parker (Eds.), The handbook of emotional intelligence. San Francisco: Jossey-Bass. 
Childs, R. (2004). Emotional intelligence and leadership. Retrieved from:

http://www.teamtechnology.co.uk/emotional-intelligence.html

Chowdhury, S. (Ed.). (2000). Management 21C. London: Pearson.

Coleman, M. (1994). Leadership in educational management. In T. Bush \& J. West-Burnham (Eds.), The principles of educational management. London: Pitman.

Coleman, M. (2003). Theories of leadership. In M. Thurlow, T. Bush \& M. Coleman (Eds.). Leadership and strategic management in South African schools. London: Commonwealth Secretariat.

Conger, J.A., \& Kanungo, R.N. (1998). Charismatic leadership in organizations. California: Sage.

Cooper, C.L. (1984). Improving interpersonal relations. London: Wilwood House.

Cooper, R., \& Sawaf, A. (1997). Executive EQ. Emotional intelligence in business. New York: Penguin.

Crawford, M. (2007). Emotional coherence in primary school headship. Educational Management, Administration \& Leadership, 35(4): 521-534.

Cyert, R.M., \& March, J.G. (1963) A behavioral theory of the firm. Englewood Cliffs, NJ: Prentice-Hall.

Dalin, P. (1994). How schools improve. London: Cassell.

Du Plessis, A., Bouwer, C., \& Eloff, I. (2002). Leadership in the enhancement of learning opportunities for all learners. In L. Calitz, O.L. Fuglestad \& S. Lillejord S (Eds.), Leadership in Education. Sandown: Heineman.

Evans, P.A.L. (2000). The dualistic leader: Thriving on paradox. In S. Chowdhury (Ed.), Management 21C. London: Prentice Hall.

Filochowski, J. (2013). Too good to fail. New York: Pearson.

Fullan, M. (2001). Leading in a culture of change. Retrieved from:

http://administration.ucok.edu/booksummaries/pdf/LeadinginaCultureofChange.pdf

Fullan, M. (2007). Leading in a culture of change. San Francisco: Jossey-Bass.

Gardner, L., \& Stough, C. (2002). Examining the relationship between leadership and emotional intelligence in senior level managers. Leadership and Organisation Development Journal, 23:68-78.

George, J.M. (2000). Emotions and leadership: The role of emotional intelligence. Human Relations, 53: $1027-1041$.

George, B., Sims, P., McLean, A.N., \& Mayer, D. (2011). Discovering your authentic leadership. In On

Leadership: HBR'S 10 most reads. Boston, Massachusetts: Harvard Business Review Press.

Goleman, D. (1996). Emotional intelligence. London: Bloomsbury.

Goleman, D. (1998). Working with emotional intelligence. New York: Bantam Books.

Goleman, D. (2004). Emotional intelligence \& working with emotional intelligence. London: Bloomsbury.

Goleman, D. (2011). What makes a leader. In HBR'S 10 must reads. Boston, Massachusetts: Harvard Business Review Press.

Goleman, D. (2013). Focus: The hidden driver of excellence. London: Bloomsbury.

Goleman, D., Boyatzis, R., \& McKee, A. (2002). Primal leadership: Realizing the power of emotional intelligence. Cambridge MA: Harvard Business School Press.

Greenberg, J. (2002). Who stole the money, and when? Individual and situational determinants of employee theft. Organizational Behavior and Human Decision Processes, 89(1): 985-1003.

Grundy, S. (1987). Curriculum: Product or praxis. London: Falmer.

Handy, C. (1989). The age of unreason. London: Business Books.

Harford, T. (2012). The undercover economist. London: Brown.

Hirschi, T. (1969). Causes of delinquency. Berkeley: University of California Press.

Hollinger, R. C., \& Clark, J. P. (1983). Deterrence in the workplace: Perceived certainty, perceived severity and employee theft. Social Forces, 62(2): 398-418.

Holloway, J. (2009). Performance management from multiple perspectives: Taking stock. International Journal of Productivity and Performance Management, 58(4): 391-399.

Ingersoll, R.M. (2007). Short on power, long on responsibility. Educational Leadership, 65(1): 20-25.

Johnson, S.M., \& Donaldson, M.L. (2007). Overcoming the obstacles to leadership. Educational Leadership, 65(1): $8-13$.

Kaplan, A. (1964). The conduct of inquiry. San Francisco: Chandler.

Kaptein, M. (2011). Understanding unethical behaviour by unravelling ethical culture. Human Relations, 64(6), 843869.

Kochan, F.K., \& Reed, C.J. (2005). Collaborative leadership, community building, and democracy in public education. In W.E. Fenwick (Ed.), The Sage handbook of educational leadership. London: Sage. 
Kotter, J.P. (2011). What leaders really do. In On Leadership: HBR'S 10 most reads. Boston,

Massachusetts: Harvard Business Review Press.

Kouzes, J.M., \& Posner, B.Z. (1997). The leadership challenge. San Francisco: Jossey-Bass.

Kouzes, J.M., \& Posner, B.Z. (2001). Bringing leadership lessons from the past into the future. In W. Bennis, G.M. Spreitzer \& T.G.Cummings (Eds.), The future of leadership. San Francisco: Jossey-Bass.

Kouzes, J.M., \& Posner, B.Z. (2012). The leadership challenge. San Francisco: Jossey-Bass.

Landy, F.G. (1985). Psychology of work behaviour. Illinois: Homewood.

Levine, S.R. (2000). The value-based edu-leader. In S. Chowdhury (Ed.), Management 21C. London: Prentice Hall.

Liddy, S. (2013). Women and emotional intelligence: The new paradigm in business. Retrieved from: http://www.huffingtonpost.com/susan-liddy-ma-pcc-cpcc/women-and-emotional-intelligence.

Manser, P.G. (2005). The influence of school principals' emotionally intelligent behaviours on the job satisfaction of educators in the Eastern Cape. (Unpublished PhD thesis). Port Elizabeth: Nelson Mandela Metropolitan University.

March, J.G., \& Olsen, J. (1984). The new institutionalism: Organizational factors in political life. American Political Science Review, 78 (3): 734-749.

Manz, C.C., \& Sims, H.P. (2001). The new super leadership. San Francisco: Berrett-Koehler.

Mayer, J.D., \& Salovey, P. (1997). What is emotional intelligence. In P. Salovey \& D. Sluyter (Eds.), Emotional development and emotional intelligence. New York: Basic Books.

Merkowitz, R.F. \& Earnest, G.W. (2006). Emotional intelligence: A pathway to self-understanding and improved leadership capacities. Retrieved from: http://www.joe.org/joe/2006august/iw3.shtml

Merriam-Webster's Medical Dictionary. (2006). Springfield, Massachusetts: Merriam-Webster, Incorprated.

Middlewood, D. (2003). Managing teacher performance and its appraisal. In J. Lumby, D. Middlewood \& E. Kaabwe (Eds.), Managing human resources in South African schools. Huddersfield: The Commonwealth Secretariat.

Miller, J.B. (1996). Best boss worst boss. New York: Fireside.

Millinger, C.S. (2004). Helping new workers cope. Educational Leadership, 61, 66-73.

Northouse, P.G. (2004). Leadership: theory and practice. London: Sage.

Ornstein, A.C., \& Hunkins, F.P. (2004). Curriculum: Foundations, principles and issues. Boston: Pearson.

Parton, N. (2000). Some thoughts on the relationship between theory and practice in and for social work. British Journal of Social Work, 30: 449-463.

Pascoe, C., Ali, I.M., \& Warne, L. (2002). Yet another role for job satisfaction and work motivation -

Enabler of knowledge creation and knowledge sharing. Insite, June, 39-48.

Pfeffer, J. \& Sutton, R.I. (2000). The knowing-doing gap. Retrieved from: http://personnel.ky.gov/NR/rdonlyres/C1C65A3B-65B4-48A1-99CC 9DD68BA78CA0/0/KnowingDoingGapKnowlBrief.pdf

Retallick, J., \& Fink, D. (2002). Framing leadership: Contributions and impediments to educational change.International Journal of Leadership in Education, 5(20): 91-104.

Senge, P.M., \& Kaufer, K.H. (2000). Communities of leaders or no leadership at all. In S. Chowdhury (Ed.), Management 21C. London: Prentice Hall.

Sergiovanni, T.J. (1991). The leadership: A reflective practice perspective. Boston: Allyn and Bacon.

Shoho, A.R., Merchant, B.M., \& Lugg, C.A. (2005). Social justice: seeking a common language. In F.W. English (Ed.), The Sage handbook of educational leadership. California: Sage.

Short, P.M. (1998). Empowering leadership. Contemporary Education, 69:70-74.

Singh, P. (2005). Use of the collegial leadership model of emancipation to transform traditional management practices in secondary schools. South African Journal of Education, 25(1):11-18.

Singh, P. (2008). Emotional intelligence begets collegial leadership in education. The International Journal of Learning, 15 (1): 73-88.

Singh, P. (2010). Innovative strategies to develop better schools. Sydney, Australia: Common Ground.

Singh, P. (2011). Tobephobia experienced by teachers in secondary schools: An exploratory study focusing on curriculum reform in the Nelson Mandela Metropole. Africa Education Review, 8(2): 372-388.

Singh, P. (2013a).Transforming traditional bureaucratic management practices by employing the Collegial Leadership Model of Emancipation. International Business and Economics Research Journal, 12(8): 953968. 
Singh, P. (2013b). Influence of the leaders' emotionally intelligent behaviours on their employees' job satisfaction. International Business and Economics Research Journal, 12(7): 799-814.

Singh, P. (2013c). A collegial approach in understanding leadership as a social skill. International Business and Economics Research Journal, 12(5): 489-502.

Singh, P. (2013d). Influence of leaders' intrapersonal competencies on employee job satisfaction. International Business and Economics Research Journal, 12(10): 1289-1302.

Singh, P. (2013e). Why it matters for collegial leaders to have a binocular vision. International Business and Economics Research Journal, 12(12): 1615-1626.

Singh, P. (2013f). Symbiotic relationship between emotional intelligence and collegial leadership. International Business and Economics Research Journal, 12(3): 331-344.

Singh, P. (2013g). Fear abounds in the educational environment: Teachers' professional competencies in the management of knowledge. International Business and Economics Research Journal, 12(6): 687-700.

Singh, P. (2014a). Intervention of transformational collegial leadership to develop human resources. International Business and Economics Research Journal, 13(1): 53-68.

Singh, P. (2014b). Employees' perceptions of the current incidence and causes of tobephobia in their working environment. International Business and Economics Research Journal, 13(4): 739-750.

Singh, P., \& Dali, C.M. (2014). Relevance of a leadership development programme to develop the leaders' workintegrated learning competencies. International Business and Economics Research Journal, 13(6): 12131230.

Singh P., \& Manser P. (2002). Collegiality in education: a case study. South African Journal of Education, 22(1): $56-64$.

Singh, P., \& Manser, P. (2008). Correlation between the perceived emotionally intelligent interpersonal behaviours of school principals and the job satisfaction of their teachers. The International Journal of Knowledge, Culture \& Change Management, 8(1), 189-200.

Singh, P., Manser, P., \& Dali, C. (2013). Principal leadership. Saarbrucken, Germany: LAP LAMBERT Academic Publishing.

Singh, P., \& Morar, T. (2009). Tobephobia: fear of failure experienced by educators. The International Journal of Knowledge, Culture and Change Management, 9(4): 93-105.

Singh, P., \& Twalo, T. (2014).Impact of human factors on the labour process: A case study. International Business and Economics Research Journal, 13(2): 305-318.

Singh, P., \& Twalo, T. (2015a). Effects of poorly implemented performance management systems on the job behavior and performance of employees. International Business and Economics Research Journal, 14(1): 79-94.

Singh, P., \& Twalo, T. (2015b). Mismanaging unethical behaviour in the workplace. Journal of Applied Business Research, 31(2): 1-16.

Snow, R.E. (1973). Theory construction for research on teaching. In R.M. Travers (Ed.), Second handbook of research on teaching. Chicago: Rand McNally.

Spillane, J.P., Halverson, R., \& Diamond, J.B. (2004). Towards a theory of leadership practice: A distributed practice. Journal of Curriculum Studies, 36(1): 3-34.

Stahl, D. (2000). What do employees expect of leaders? Nursing Management, 31, 58-59.

Stein, S.J., \& Book, H.E. (2001). The EQ edge: Emotional intelligence and your success. New York: Stoddart.

Sterrett, E.A. (2000). Amherst, Massachusetts: HRD Press.

Taba, H. (1962). Curriculum development: Theory and practice. New York: Harcourt Brace Jovanovich.

The Standard. (2014). How to survive stress. December 2014, Issue number 133.

Thilo, J.L. (2004). Emotional intelligence and leadership in the ASC. American Association of Ambulatory Surgery Centers. Retrieved from: http://www.aaasc.org/features/monitor2003/FEA_030903 EmotionalIntelligenceLeadership. html

Vermeulen, S. (1999). EQ. Emotional intelligence for everyone. Rivonia: Zebra Press.

Williams, K. (1989). The case for democratic management in schools. Irish Education Studies.

Yukl, G. (1998). Leadership in organisations. Saddle River: Prentice Hall. 